ground. The duration of the larval days. stages was as follows.- Ist stage, 5 Food-plan's : Hamamelis vir-

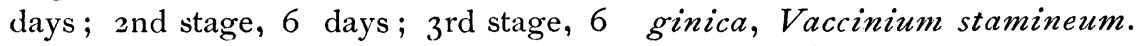
days, $4^{\text {th }}$ stage, 7 days; $5^{\text {th }}$ stage, 7 Larvae from Ulster Co., N. Y.

\title{
THE NUMBER OF MOLTS OF LEPIDOPTEROUS LARVAE.
}

\section{BY HARRISON G. DYAR, RHINEBECK, N. Y.}

Two articles have already appeared in Psyche on this subject* and it is evident from a perusal of them that considerable confusion exists as to the number of molts of certain species. In this article I propose to establish a criterion by which different observations may be compared and errors detected, for it is no difficult thing to overlook a molt or even to think one has occurred when it has not.

It will be seen by an examination of the following figures that the widths of the head of a larva in its successive stages follow a regular geometrical progression, and if, in examining the measurements of heads taken in following out a life history, any deviation from the calculated progression is shown, it is evidence that an error has been committed or that the larva has behaved in an abnormal manner; but the latter case can readily be distinguished from the former if a moderate degree of care has been exercised in taking the measurements. Hence, if two sets of observations show a different number of stages for the same insect but each

* W. H. Edwards, Psyche, v. 3, p. 159.

A. K. Dimmock, Psyche, v. 5, p. 28. follows its own progression, we may conclude that this variation is actual; but if either set shows a lack of regular progression that one we must regard with suspicion. Corroborative observations of the kind indicated are to be desired and until we have them we can not speak with confidence about the number of molts of any species. I recommend that all who hereafter describe larval stages give the width of the head for each stage. I have selected the head as the part not subject to growth during the stage, and its width as the most convenient measurement to take.

In the following I give first the calculated widths of head under each species, with the ratio, followed by those that were actually found. All measurements are in millimeters and may be considered accurate to within . I mm. Certain irregularities are commented upon in the notes to which the small numbers refer.

FOUR STAGES.

Callosamia promethea Drury. calc. r.I r.6 $2.33 .3, \mathrm{r} .7 \mathrm{O}$ found 1.0 I.7 $2.33 .3^{1}$ 
FIVE S'TAGES.

Pupilio cresphontes Cram. calc. .7 I.I $1.62 .33 .4, \mathrm{r} .68$

found .6 I. I $1.6 \quad 2.2 \quad 3.4$

Eudamus tityrus, Fabr. calc. .6 I.o 1.7 $2.84 .7, x .60$

found $\left\{\begin{array}{l}.6 \text { I. I } 1.82 .5^{2}- \\ -1.73 .2^{3} 4.7\end{array}\right.$

Syntomeida epilais, Walk. calc. 6 $\begin{array}{llllll}.8 & 1.1 & 1.5 & 2, \mathrm{r} & .73\end{array}$

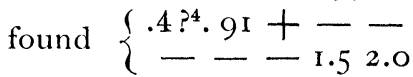

Datana drexelii Hy. Edw. calc. 6 I. I

I.9 $3.25 .4, \mathrm{r} .6 \mathrm{o}$

found .5 I.I $1.7-1.9 \quad 3.25 .4$

Datana major G. \& R. calc. 6 I.o I.8

$$
3 \cdot \mathrm{I} 5 \cdot 3, \mathrm{r} \cdot 5^{8}
$$

found .5 I.I I.7 3. I $5 \cdot 3$

Datana palmii Beut. calc. .5 .9 I.5

$2.74 .6, \mathrm{r} .58$.

found $.5 \quad .9 \quad$ r. $6 \quad 2.7 \quad 4.6$

Datana integerrima G. \& R. calc. $\cdot 5$

$\begin{array}{llll}.9 & 1.6 & 2.6 & 4.3 \\ & \mathrm{r} & 6 \mathrm{o}\end{array}$

found - . .9 $1.6 \quad 2.7 \quad 4.3$.

Datına perspicua G. \& R. calc .7 I.I

I.7 $2.74 . \mathrm{I}, \mathrm{r} .65$

found .5 I. I I.6-8 2.7 4. I

Oedemasia concinna A. \& S. calc. .45 .7 I.I I.75 $2.7, \mathrm{r} .65$

found $\left\{\begin{array}{l}.4 \text { I.0 }{ }^{5} \mathrm{I} \cdot 3-\frac{1}{-} \text { I.I } 1.72 .7\end{array}\right.$

Schizura leptinoides Grote calc. .5 .S

$$
\mathrm{I} \cdot 32.13 .3, \mathrm{r} .64
$$

found .5 .8 1.5 $2.1 \quad 3.3$

Schizura ipomeae Doubl. calc. .6.9 I.4

$$
2.23 .3, \mathrm{r} .66
$$

$$
\text { found }-1.52 .23 .3^{6}
$$

Heterocampa subrotata Harv. $q$ calc.

$\begin{array}{llllll}.7 & \text { I.I } & \text { I.7 } & 2.6 & 3.9, & \text { r.66 }\end{array}$

found $.6 \quad$ i. I $1.72 .6 \quad 3.8$

Heterocampa unicolor Pack. calc. .5 .8
$\mathrm{I} \cdot 32.03 .2, \mathrm{r} 64$.

found $.4 .7 \quad 1.35 \quad 2.1 \quad 3.2$

Platysamia cecropia Linn. calc. I.I

$$
1.62 .43 .65 .5, \mathrm{r} .66
$$

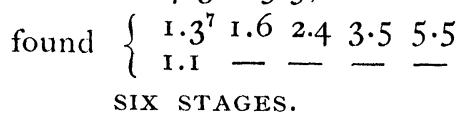

Euchaetes egle Harr. calc. .45 .6 9

I.3 I.9 $2.7, \mathrm{r} .7 \mathrm{O}$

found $-.6 .9 \quad 1.32 .027$

Edema albifrons S. \& A. calc. .4.6

I.O $1.72 .7 \quad 4.3, \mathrm{r} .62$

found $\left\{\begin{array}{llllll}.4 & .7 & 1.3 & 1.7 & 2.3 & -8 \\ .4 & .7 & 1.3 & 1.7 & 2.2 & 3.2\end{array}\right.$

Dryopteris rosea Walk. calc. .25 .4 .6 .9 r.3 2. $1, \mathrm{r} .66$

found $.3 \cdot 4 \cdot 69 \cdot 1.32 .2$

Hyperchiria io Fabr. calc. 8 I.I I.7

$2.43 .55 .1, r .69$

found $.8 \quad 1.2 \quad 1.7 \quad 2.6 \quad 3.45 .1$

Clisiocampa americana Har. calc. .4 $\begin{array}{llllll}.6 & .9 & 1.3 & 2.0 & 3.0, & \text { r. .66 }\end{array}$

found $\left\{\begin{array}{llllll}.4 & .6 & - & - & - & -\end{array}\right.$

Agrotis incivis Guen. calc. .4 .6 .9 I.3 $2.03 .0, \mathrm{r} .66$

found $.2^{9} .7 ? .9 \quad 1.32 .03 .0$

SEVEN STAGES.

Halisidota harrisii Walsh. calc. .4 .6 $\begin{array}{llllll}.8 & 1.2 & 1.7 & 2.4 & 3.5 & \mathrm{r} .70\end{array}$

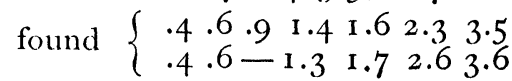

Hyphantria cunea Drury. calc. $\cdot 3 \cdot 4$ $.6 .81 .21 .7 \quad 2.4, \mathrm{r} .70$

found $\left\{\begin{array}{lll}.3 .4 & .6 .81 .21 .4^{10}- \\ - & -\end{array}\right.$

Orgyia definita Pack. $\$$ calc. $.5 \cdot 7$ I.o

I.4 $2.02 .84 .0, \mathrm{r} .70$

found -.7 I.O $1.52 .12 .83 .5^{11}$

EIGHT STAGES.

Scepsis edwardsii Grote. calc. · · $\cdot 4$ 


$$
\begin{aligned}
& .9 \quad 1.2 \quad 1.6 \quad 2.2 \quad 3.0, r .73 \\
& \text { found }\left\{\begin{array}{lllll}
\frac{.4}{4} .5 & .7 & .9 & .1 .2 & 1.6
\end{array}\right. \\
& \text { NINE STAGES. }
\end{aligned}
$$

Halisidota caryae Harr. calc. .5 • .7 .9 I.2 1.6 2.0 $2.63 .44 .3, \mathrm{r} .78$ found $.4 .6-12$ I.2 I.5 $2.1 \quad 2.7$ $3 \cdot 4 \quad 4 \cdot 4$

Halisidota tesselaris S. \& A. calc. $\cdot 5$ $\begin{array}{lllllll}.7 & .9 & \text { I.2 } & \text { I.6 } & 2.0 & 2.6 & 3.4\end{array}$ $4 \cdot 3, r .78$

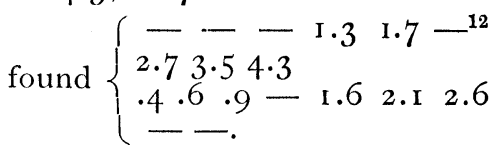

TEN STAGES.

Pyrrharctia isabella A. \& S. calc. .4 $\cdot 5$ $\begin{array}{lllllll}.7 & .9 & \text { I.I } & 1.6 & 2.0 & 2.6 & 3.2\end{array}$ $4 \cdot r, r \cdot 79$

found $.4 \cdot 5 \cdot 7 \cdot 9 \quad 1.2 \quad$ I.6 $2.2 \quad 2.6$ $3.6^{13} 4.1$

\section{NOTES.}

${ }^{1}$ It will be seen that I corroborate the observations of $\mathrm{Mr}$. W. H. Edwards in giving four stages to this species, and as my specimens were bred in Rhinebeck, N. Y. the theory of variation in the number of molts due to climatic influence suggested by Mrs. Dimmock (Psyche, v. 5. p. 29) does not appear to be sustained.

2 'This measurement, $2.5 \mathrm{~mm}$., is too small as the larva was unable to cast its skin and the head was dwarfed.

${ }^{3}$ 'This is too large; it is possibly an error of observation and was not verified.

${ }^{4}$ An incorrect measurement. I find it marked with an (?) in my notes.

${ }^{5}$ A remarkable instance of excessive development. I do not think any error was made. The second example behaved in a normal manner as can be seen from what measurements I have.

${ }^{6} \mathrm{My}$ observations do not agree with those of Dr. Packard on this species, who finds six stages. (Proc. Bost. soc. nat. hist. v. 24, p. 534.)

${ }^{7}$ The second example has the normal measurement. Possibly I have made an error in the first measurement.

${ }^{8}$ It will be seen that in both examples no series is followed, but both larvae became unhealthy and died in the fifth and sixth stages respectively which probably accounts for the dwarfed dimensions of their heads. This is one of the instances of abnormal development which is readily distinguishable from an error of omission.

For examples of the latter see note ( $\left.{ }^{12}\right)$.

In giving six stages to this species I corroborate the observations of $\mathrm{Mr}$. Beutenmüller (Ent. Amer., v. 6, p. 75) but disagree with Dr. Packard who finds but five stages. (Proc. Bost. soc. nat. hist., v. 24, p. 525.)

${ }^{9}$ An erroneous measurement. It is marked in my notes as carelessly taken.

10 This larva died in the sixth stage and its head is seen to have been dwarfed.

11 The last stage, width of head $3.5 \mathrm{~mm}$., occurs only in larvae that produce female moths and it is seen to be too small for the series. I intend to make more observations on this species and will not comment on it further at this time.

${ }^{12}$ Examples of accidental omissions which were not detected at the time and which would have gone entirely unrecognized had it not been for the measurements recorded. On making calculations and observing the apparent omissions I endeavored to obtain more larvae. No young caryae were to be had, but some tesselaris, carefully watched exhibited the missing stage as may be seen from the second example.

${ }^{13}$ Probably an error. I found this larva very difficult to measure and this particular stage was not verified by measuring the cast head as most of the others were. 

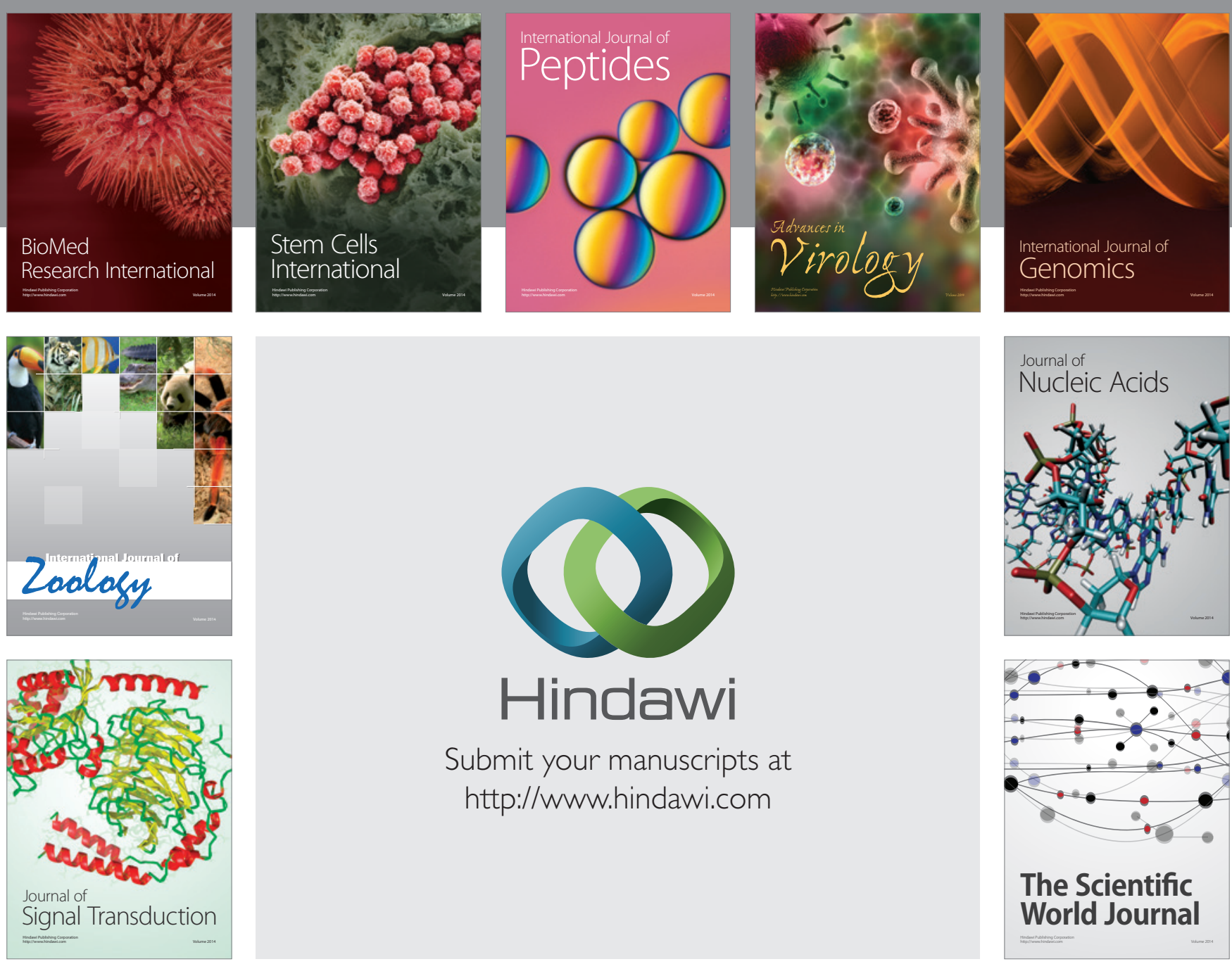

Submit your manuscripts at

http://www.hindawi.com
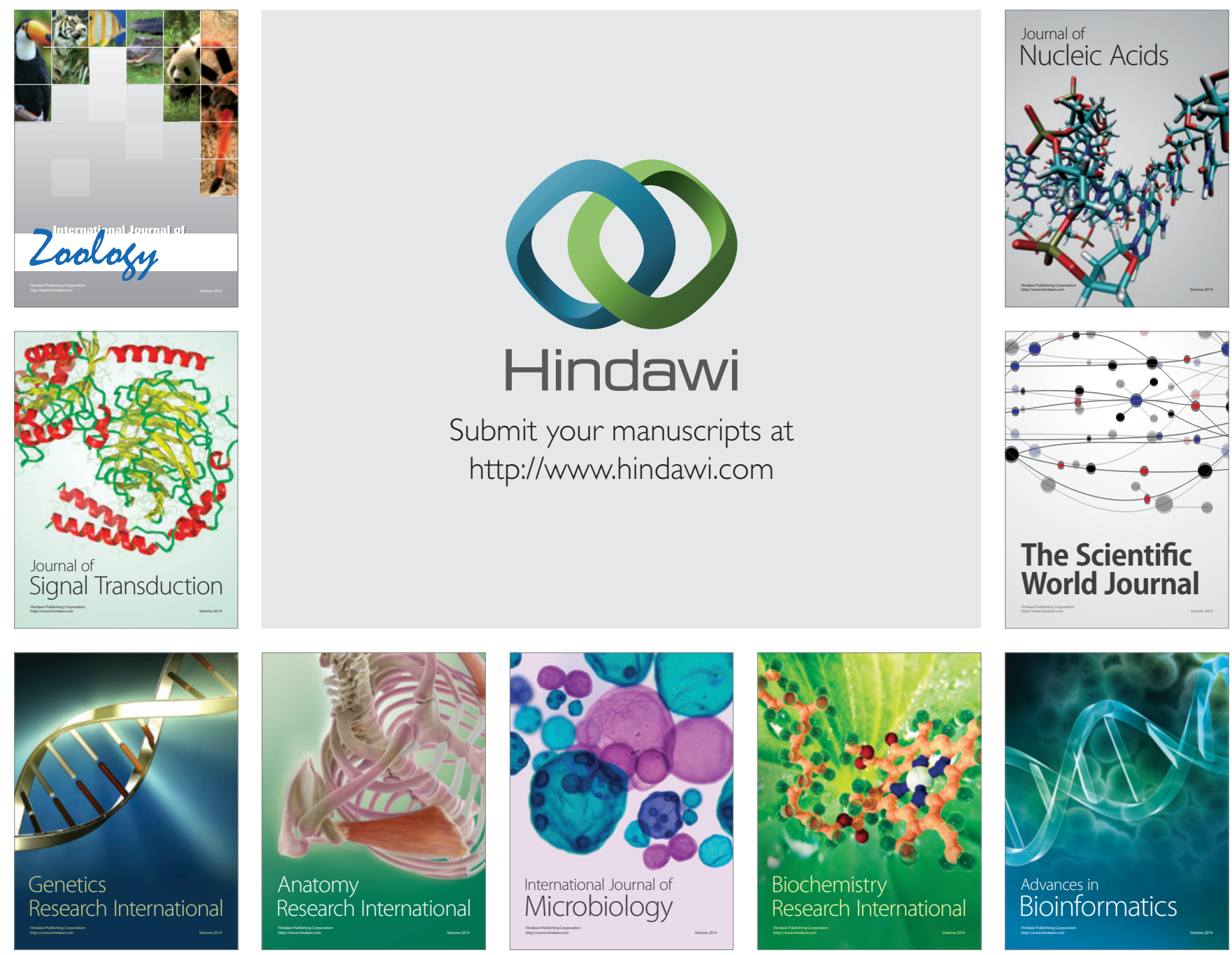

The Scientific World Journal
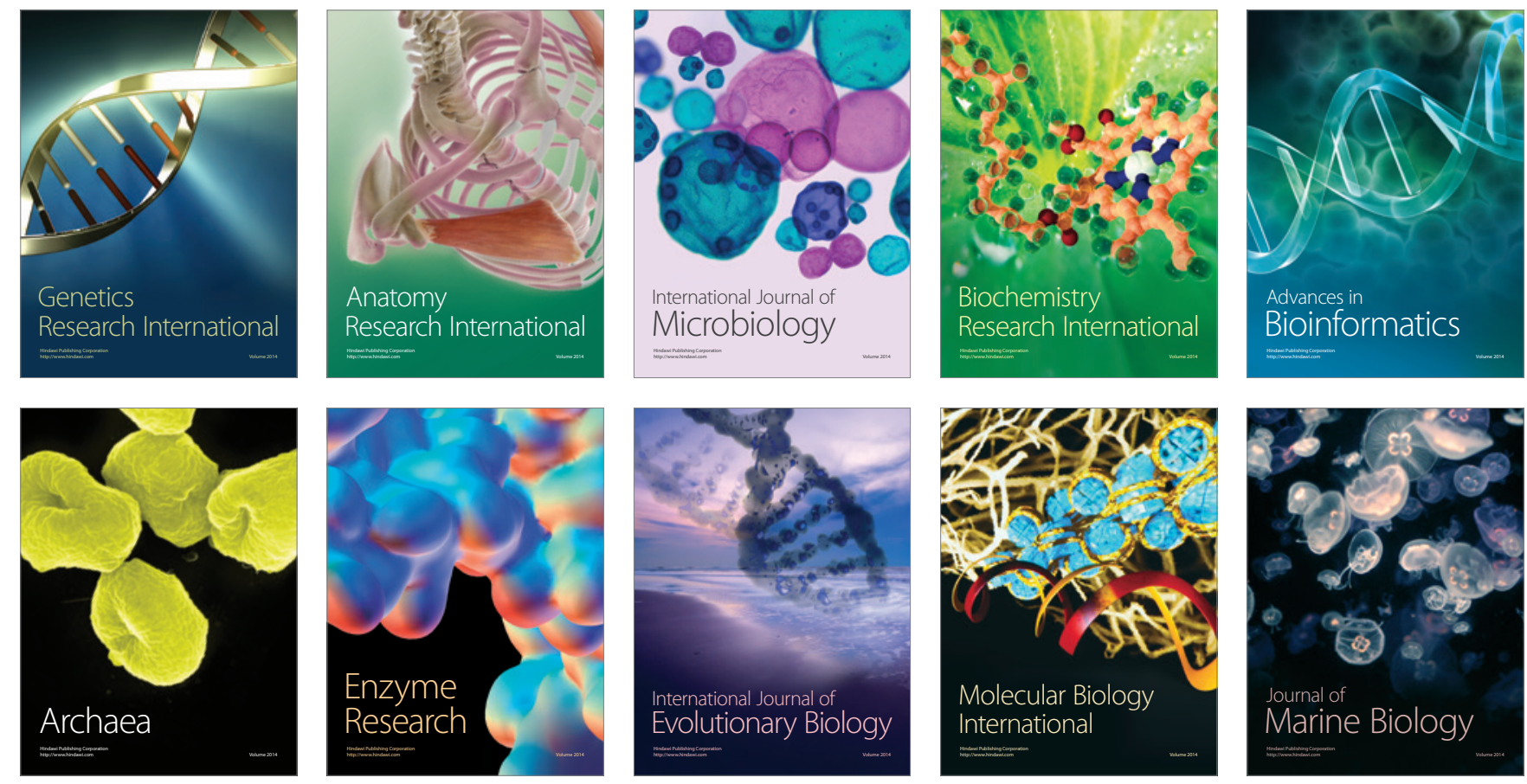